\title{
Effective roughness modelling as a tool for soil moisture retrieval from C- and L-band SAR
}

\author{
H. Lievens ${ }^{1}$, N. E. C. Verhoest ${ }^{1}$, E. De Keyser ${ }^{2}$, H. Vernieuwe ${ }^{2}$, P. Matgen ${ }^{3}$, J. Álvarez-Mozos ${ }^{4}$, and B. De Baets ${ }^{2}$ \\ ${ }^{1}$ Laboratory of Hydrology and Water Management, Ghent University, Coupure links 653, 9000 Ghent, Belgium \\ ${ }^{2}$ Department of Applied Mathematics, Biometrics and Process Control, Ghent University, Coupure links 653, 9000 Ghent, \\ Belgium \\ ${ }^{3}$ Department of Environment and Agro-Biotechnologies, Public Research Centre Gabriel Lippmann, rue du Brill 41, 4422 \\ Belvaux, Luxembourg \\ ${ }^{4}$ Department of Projects and Rural Engineering, Public University of Navarre, Arrosadia s/n, 31006 Pamplona, Spain
}

Received: 5 July 2010 - Published in Hydrol. Earth Syst. Sci. Discuss.: 29 July 2010

Revised: 23 December 2010 - Accepted: 12 January 2011 - Published: 17 January 2011

\begin{abstract}
Soil moisture retrieval from Synthetic Aperture Radar (SAR) using state-of-the-art backscatter models is not fully operational at present, mainly due to difficulties involved in the parameterisation of soil surface roughness. Recently, increasing interest has been drawn to the use of calibrated or effective roughness parameters, as they circumvent issues known to the parameterisation of fieldmeasured roughness. This paper analyses effective roughness parameters derived from C- and L-band SAR observations over a large number of agricultural seedbed sites in Europe. It shows that parameters may largely differ between SAR acquisitions, as they are related to the observed backscatter coefficients and variations in the local incidence angle. Therefore, a statistical model is developed that allows for estimating effective roughness parameters from microwave backscatter observations. Subsequently, these parameters can be propagated through the Integral Equation Model (IEM) for soil moisture retrieval. It is shown that fairly accurate soil moisture results are obtained both at Cand L-band, with an RMSE ranging between $4 \mathrm{vol} \%$ and $6.5 \mathrm{vol} \%$.
\end{abstract}

\section{Introduction}

Soil moisture $\left(M_{\mathrm{v}}\right)$ is of paramount importance in the hydrologic cycle, as it determines the partitioning of rainfall into runoff and infiltration, affects the evapotranspiration rate and drives crop development. It is well known that Synthetic Aperture Radar (SAR) sensors have a large potential for ob-

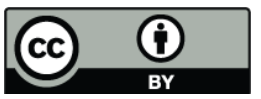

Correspondence to: H. Lievens (hans.lievens@ugent.be) serving soil moisture. During the past decades, many efforts have been made to develop robust backscatter models that allow soil moisture retrieval from SAR, ranging from empirical relationships (e.g. Oh et al., 1992; Wang et al., 1997; Zribi and Dechambre, 2002) to physical approximations (e.g. Rice, 1951; Beckman and Spizzichino, 1963; Fung, 1994). Amongst the latter, the single scattering approximation of the Integral Equation Model (IEM) (Fung et al., 1992; Fung, 1994) is the most frequently used when concerned with bare or sparsely vegetated agricultural soils (Moran et al., 2004).

The backscattering of microwaves from a soil surface not only depends on the soil moisture content, but also on the soil surface roughness. Despite the continuing advances in surface roughness parameterisation from field measurements (e.g. Oh and Kay, 1998; Davidson et al., 2000; Jester and Klik, 2005; Callens et al., 2006) and SAR observations (e.g. Borgeaud and Noll, 1994; Mattia et al., 1997; Srivastava et al., 2008; Marzahn and Ludwig, 2009), the use of these roughness parameters for soil moisture retrieval from SAR often remains unsatisfactory. Several studies have attributed this to an inadequate processing of roughness measurements on the one hand (e.g. Bryant et al., 2007; Lievens et al., 2009), or to a failure of the backscatter models in describing the complexity of surface roughness on the other hand (e.g. Mattia et al., 2003; Wagner et al., 2007). Most physically-based models such as the IEM assume that surface roughness is a single-scale random stationary process characterised in terms of the Root Mean Square (RMS) height, $s$, the correlation length, $l$, and an autocorrelation function (ACF) (Fung et al., 1992). However, natural surfaces are generally non-stationary and should be regarded as a superposition of single- and multiscale processes, respectively related to agricultural tillage effects and long-term shaping (Davidson et al., 2000; Mattia et al., 2003). As a consequence,

Published by Copernicus Publications on behalf of the European Geosciences Union. 
Table 1. Overview of the collected data sets.

\begin{tabular}{|c|c|c|c|c|c|c|c|c|c|c|}
\hline Band & $\begin{array}{l}\text { Site } \\
\text { ID }\end{array}$ & Site & Date & $\begin{array}{c}\# \\
\text { Fields }\end{array}$ & $\begin{array}{c}\# \\
\text { Images }\end{array}$ & SAR data & $\theta\left({ }^{\circ}\right)$ & Texture (USDA) & $M_{\mathrm{V}}$ sampling & Reference \\
\hline \multirow[t]{5}{*}{$\mathrm{C}-\mathrm{HH}$} & 1 & Alzette (L) & 2007-2009 & 2 & 6 & ENVISAT ASAR & $17.2-24.6$ & (sandy) clay loam & grav. $(0-5 \mathrm{~cm})$ & - \\
\hline & & & & & 1 & RADARSAT-1 & $22.1-24.1$ & (sandy) clay loam & grav. $(0-5 \mathrm{~cm})$ & - \\
\hline & 2 & Dijle (B) & 2007-2009 & 3 & 6 & ENVISAT ASAR & $15.0-29.1$ & silt & grav. $(0-5 \mathrm{~cm})$ & - \\
\hline & & & & & 2 & RADARSAT-1 & $26.7-30.1$ & silt & grav. $(0-5 \mathrm{~cm})$ & - \\
\hline & 3 & La Tejería (E) & 2003 & 15 & 5 & RADARSAT-1 & $15.0-28.7$ & silty clay & TDR $(0-11 \mathrm{~cm})$ & Álvarez-Mozos et al. $(2006,2008)$ \\
\hline \multirow[t]{8}{*}{$\mathrm{C}-\mathrm{VV}$} & 4 & Alzette (L) & 2007-2009 & 2 & 10 & ENVISAT ASAR & $17.2-26.4$ & (sandy) clay loam & grav. $(0-5 \mathrm{~cm})$ & - \\
\hline & 5 & Dijle (B) & $2007-2009$ & 3 & 8 & ENVISAT ASAR & $15.0-29.1$ & silt & grav. $(0-5 \mathrm{~cm})$ & - \\
\hline & 6 & La Tejería (E) & 2004-2005 & 10 & 6 & ENVISAT ASAR & $15.5-31.3$ & silty clay & TDR $(0-11 \mathrm{~cm})$ & Álvarez-Mozos et al. (2009) \\
\hline & 7 & Loamy region (B) & 2003 & 10 & 1 & ERS-2 SAR & $20.1-20.5$ & silt & $\begin{array}{l}\text { grav. }(0-5 \mathrm{~cm}) / \\
\text { TDR }(0-11 \mathrm{~cm})\end{array}$ & Verhoest et al. (2007a) \\
\hline & 8 & Matera (I) & 1998 & 5 & 1 & ERS-2 SAR & 23 & silty clay & grav. $(0-5 \mathrm{~cm})$ & Verhoest et al. (2007a) \\
\hline & 9 & Zwalm (B) & 1995 & 6 & 2 & ERS-1/2 SAR & $18.9-23.2$ & silt loam & grav. $(0-10 \mathrm{~cm})$ & Verhoest et al. (2000) \\
\hline & 10 & Zwalm (B) & 1996 & 3 & 2 & ERS-1/2 SAR & $20.5-23.2$ & silt loam & grav. $(0-10 \mathrm{~cm})$ & Verhoest et al. (2000) \\
\hline & 11 & Zwalm (B) & 2003 & 6 & 2 & ERS-2 SAR & $21.7-23.7$ & silty clay loam & $\begin{array}{l}\text { grav. }(0-5 \mathrm{~cm}) / \\
\text { TDR }(0-11 \mathrm{~cm})\end{array}$ & Verhoest et al. (2007a) \\
\hline \multirow[t]{4}{*}{ L-HH } & 12 & Alzette (L) & 2007-2009 & 2 & 2 & ALOS PALSAR & $36.5-41.1$ & (sandy) clay loam & grav. $(0-5 \mathrm{~cm})$ & Heitz et al. (2009) \\
\hline & 13 & Dijle (B) & $2007-2009$ & 3 & 4 & ALOS PALSAR & $36.2-39.4$ & silt & grav. $(0-5 \mathrm{~cm})$ & - \\
\hline & 14 & Zwalm (B) & 2007 & 2 & 1 & ALOS PALSAR & 38.7 & silt loam & grav. $(0-10 \mathrm{~cm})$ & Lievens et al. (2008) \\
\hline & 15 & Demmin (D) & 2006 & 2 & 5 & E-SAR & $39.1-50.7$ & sandy loam & $\begin{array}{l}\text { grav. \& TDR } \\
(0-10 \mathrm{~cm})\end{array}$ & Hajnsek et al. (2007) \\
\hline
\end{tabular}

the parameterisation of roughness in terms of $s, l$, and ACF is problematic (see Verhoest et al. (2008) for a topical review) and often reported as being the main error source contributing to poor soil moisture retrieval results (e.g. Rakotoarivony et al., 1996; Zribi et al., 1997; Leconte et al., 2004). Several attempts have been made to enhance conventional backscatter models through a self-affine or fractal surface description (e.g. Mattia and Le Toan, 1999; Zribi et al., 2000; Franceschetti et al., 2000). However, a fractal surface description increases the complexity and number of parameters, limiting the operational use of such methods. Therefore, present soil moisture retrieval research keeps being driven by models assuming a stationary surface. As an alternative solution to the parameterisation problems associated with single-scale backscatter models, roughness parameters are often calibrated. Such a technique was initially introduced by Su et al. (1997), who used backscatter and soil moisture observations of a first acquisition date to estimate a roughness parameter, referred to as the effective roughness parameter, which could further replace in situ measurements of roughness for the retrieval of soil moisture from subsequent SAR acquisitions. However, recent studies (Baghdadi et al., 2004, 2006) have shown that effective roughness parameters of the same site may diverge significantly when derived from different SAR acquisitions with specific sensor configurations. As a result, the use of temporally constant effective roughness parameters for soil moisture retrieval from subsequent acquisitions may not be justified.

This paper analyses the behaviour of effective roughness parameters, both RMS height and correlation length, as derived from C- and L-band SAR observations over a large number of bare or sparsely vegetated seedbed fields within different sites in Europe. Based on this analysis, a statistical model is developed that allows the estimation of improved parameters for each new SAR acquisition. Subsequently, the derived roughness parameters are propagated through an iterative inversion scheme of the IEM and the four-component dielectric mixing model (Dobson et al., 1985) for the retrieval of soil moisture. Finally, the accuracy of the retrieved soil moisture values and the robustness of the retrieval technique are evaluated through a cross-validation with in situ measurements.

\section{Study sites and data}

A large number of SAR acquisitions and corresponding field observations were collected over agricultural fields located within different study sites in Europe. The SAR data comprises spaceborne (ENVISAT, RADARSAT-1 and ERS1/2) C-band acquisitions operated at a Horizontal-Horizontal $(\mathrm{HH})$ and Vertical-Vertical (VV) polarisation, as well as spaceborne (ALOS) and airborne (E-SAR) L-band acquisitions at $\mathrm{HH}$ polarisation. The study fields were selected based on two important criteria. First, only bare soils or sparsely vegetated fields were considered, which justifies the use of a surface scattering model such as the IEM. Second, fields were required to display smooth roughness conditions, associated with rotary tillage or seedbed preparation, and were not tilled during the acquisition period. It is worth mentioning that such smooth surface roughness conditions are found during most of the year in cereal cropping areas such as those investigated in this study. Table 1 gives an overview of the study sites, the SAR observations and the performed soil moisture measurements. Regarding the soil moisture measurements, both the sampling technique, i.e. gravimetric (grav.) or Time Domain Reflectometry (TDR), and measurement depth are indicated. The gravimetric measurements were obtained after weighing and oven drying $\left(24 \mathrm{~h}\right.$ at $\left.105^{\circ}\right)$, and were converted into the volumetric moisture content 

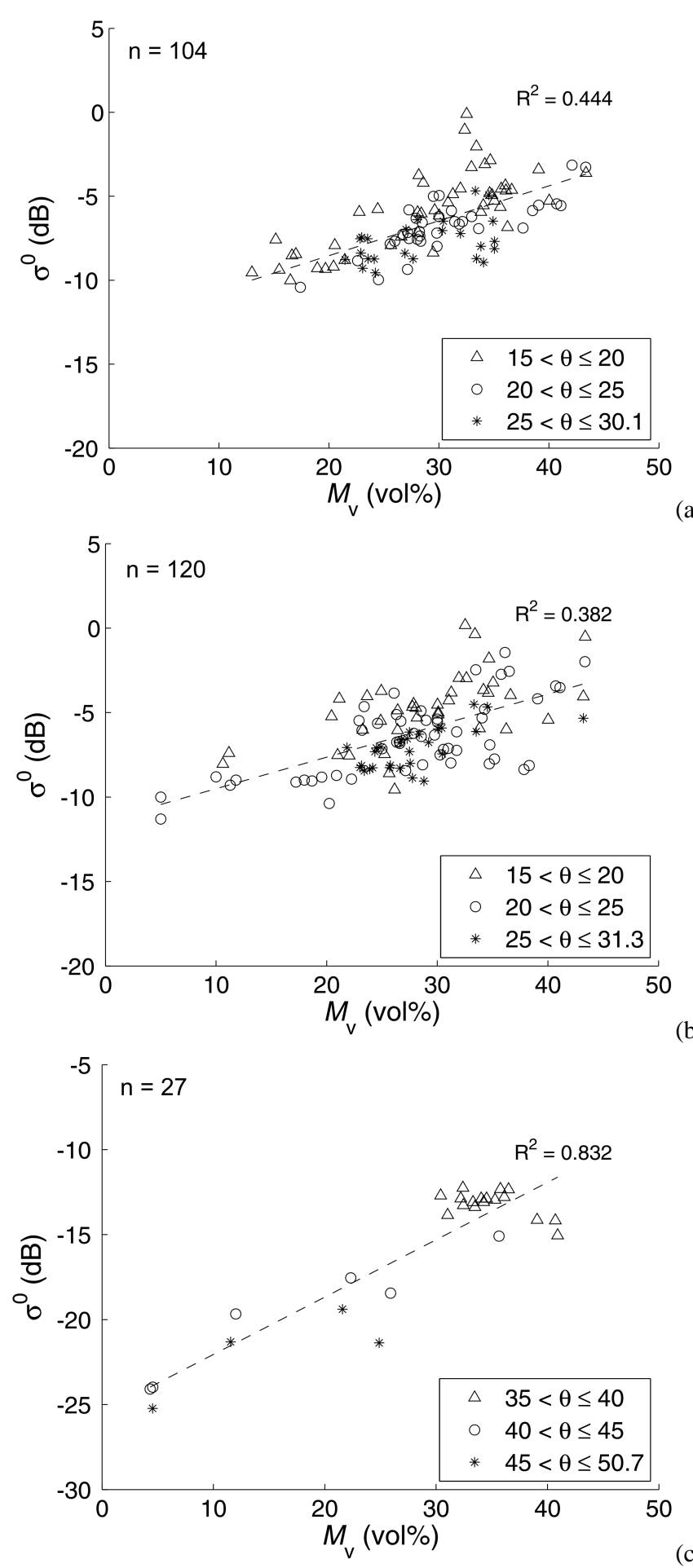

(b)

(c)

Fig. 1. Sensitivity of backscatter $\left(\sigma^{0}\right)$ to in situ soil moisture $\left(M_{\mathrm{V}}\right)$ for different intervals of local incidence angle $(\theta)$ at (a) C-band $\mathrm{HH}$, (b) C-band VV and (c) L-band $\mathrm{HH}$ configuration; $n$ is the number of data points. using measurements of the bulk density. Finally, Table 1 also provides references to the literature for a more comprehensive description.

A more detailed data analysis has been performed for two sites, La Tejería (ID 3) and Demmin (ID 15), as they were both covered by cereal vegetation that was already in a further development stage. La Tejería is a small watershed (170 ha) located in the region of Navarre (North of Spain). During the RADARSAT- 1 acquisitions in 2003, the watershed was almost completely cultivated, with winter cereals being the main cropping system. The fifteen selected study fields were recently sown with winter wheat and winter barley. However, despite the average development of the vegetation, it will not be accounted for in this study, as the effect of the vegetation was minimised given the low incidence angles (swath modes S1 and S2) and the HH polarisation of the RADARSAT acquisitions (Biftu and Gan, 1999). This negligible effect could be verified through application of a water cloud model (Attema and Ulaby, 1978; Prévot et al., 1993), using leaf area index (LAI) and vegetation water content (VWC) as bulk canopy parameters. For LAI and VWC respectively ranging from 2.149 to 3.711 and 0.661 to $1.317 \mathrm{kgm}^{-2}$, the attenuation of the backscatter through the canopy was compensated to a large extent by a direct vegetation contribution, leading to insignificant vegetation corrections within the relative radiometric accuracy of the RADARSAT observations, i.e. $+/-1 \mathrm{~dB}$ (Srivastava et al., 1999). The Demmin (Durable Environmental Multidisciplinary Monitoring Information Network) test site is situated in Mecklenburg-Western Pomerania, approximately $150 \mathrm{~km}$ north of Berlin (Germany). Because of its flat topography and large cultivated fields ( 225 ha on average), this site is extremely suitable for earth observation studies. Therefore, it was selected by ESA for the AgriSAR 2006 campaign (Hajnsek et al., 2007). Between mid-April and the end of July 2006, the German Aerospace Centre (DLR) carried out twelve full-polarimetric airborne E-SAR (Experimental SAR) flights in East-West direction over the area. Coincidently, soil moisture measurements were performed at several locations within two study fields sown with winter wheat. To minimise the effect of the wheat vegetation, only the first three and last two acquisitions are used in this study. During these acquisitions, the vegetation was characterised by a relatively low volumetric plant water content (VWC $<1.7 \mathrm{kgm}^{-2}$ ), which is often reported as being the driving factor for direct canopy backscatter (e.g. Attema and Ulaby, 1978; Bindlish and Barros, 2001). As illustrated by Lievens and Verhoest (2010), the impact of the wheat vegetation was found to be well below the noise level of the E-SAR, i.e. $<2 \mathrm{~dB}$ (Scheiber et al., 2008), for these specified acquisitions, justifying the use of a surface scattering model as the IEM.

For all study sites, standard processing techniques were employed, including image calibration, calculation of backscatter coefficients $\left(\sigma^{0}\right)$ and geocoding. As a 

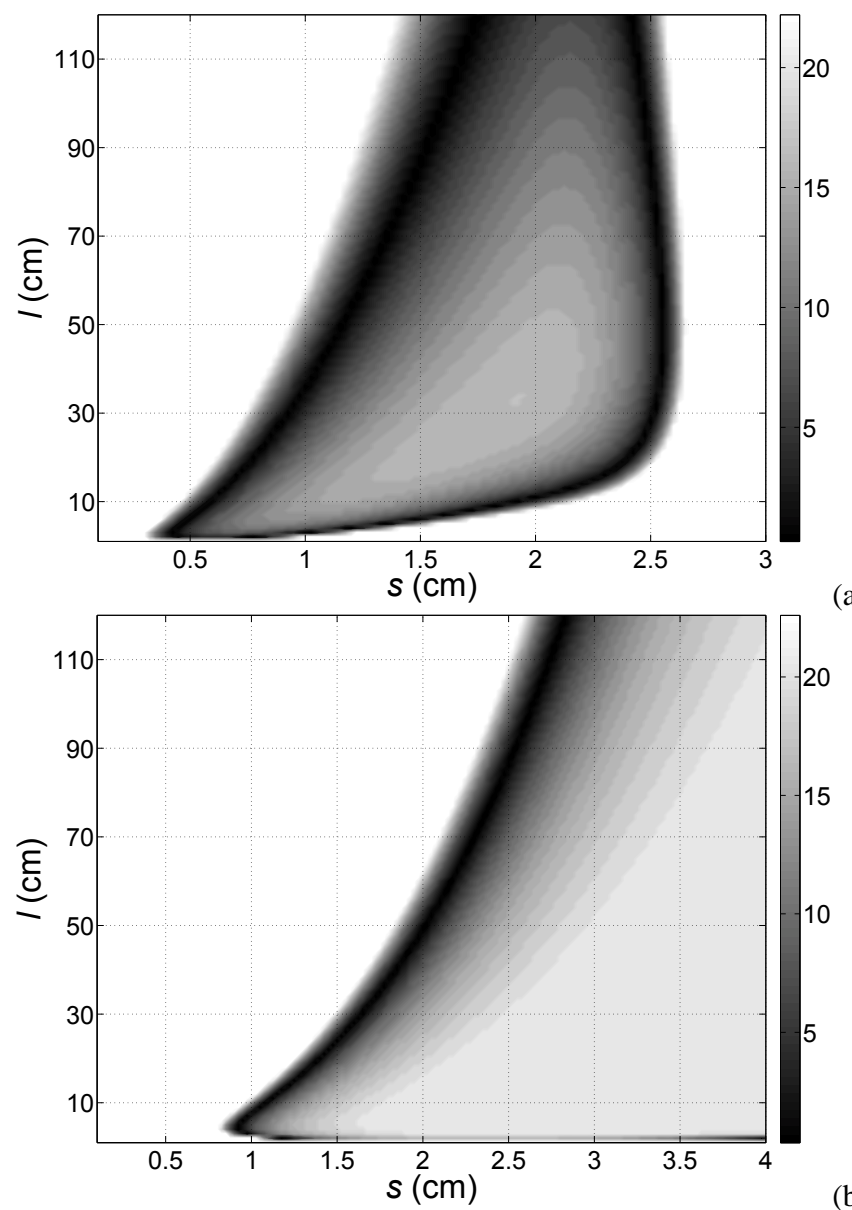

(a)

Fig. 2. Absolute soil moisture retrieval error (vol\%) for different $(s, l)$-combinations and a given $\left(\sigma^{0}, M_{\mathrm{V}}\right)$-observation using (a) C-band HH (RADARSAT-1 acquisition of La Tejería, with $\sigma^{0}=$ $-5.93 \mathrm{~dB}$ and $M_{\mathrm{v}}=22.76 \mathrm{vol} \%$ ) and (b) L-band HH (E-SAR acquisition of Demmin, with $\sigma^{0}=-17.55 \mathrm{~dB}$ and $M_{\mathrm{V}}=22.34 \mathrm{vol} \%$ ).

final processing step, the $\sigma^{0}$-observations and in situ $M_{\mathrm{v}}$ observations (ranging from 3 to 40 samples per field) were averaged on a field scale level in order to reduce uncertainty. Figure 1 shows these field averaged backscatter and soil moisture observations of all sites per SAR configuration. As this figure illustrates, the highest correlation between soil moisture and backscatter is found at L-band, highlighting the large potential of lower frequency SAR for soil moisture retrieval. On the other hand, C-band VV reveals the lowest correlation. However, it should be remarked that a direct comparison between configurations may not be justified because of differences in the size of the data sets and data acquisition, e.g. C-band data are acquired at lower incidence angle than L-band data. Particularly for C-band VV, additional errors may be introduced by merging a large number of study sites, which, by consequence, yields a larger set of unique and dispersed field conditions. Finally, errors may originate from combining different soil moisture sampling procedures and from differences in the processing of the SAR imagery. Nevertheless, we believe that the combination of data sets contributes to the quality assessment of the developed retrieval technique and to the evaluation of its robustness.

\section{The effective roughness approach}

The effective roughness approach was first introduced by $\mathrm{Su}$ et al. (1997) and makes use of backscatter and soil moisture observations for the estimation of a roughness parameter. This effective roughness parameter can then replace in situ measurements of roughness for the retrieval of soil moisture from successive SAR images. Su et al. (1997) first applied this technique using the IEM to obtain surface RMS slope $(s / l)$ as effective parameter, reducing the number of unknowns in the model. Later on, Verhoest et al. (2000) applied a similar technique to retrieve effective $s$-values for the Oh model (Oh et al., 1992), using ERS and SIR-C data of the Zwalm catchment (Belgium). This resulted in a significant improvement of soil moisture retrieval compared to conventional techniques. More recently, Baghdadi et al. (2002, 2004, 2006) calculated effective $l$-values based on the IEM and measurements of $s$. They found that effective $l$-values of the same site may diverge significantly when derived from different SAR acquisitions with specific sensor configurations. Therefore, empirical equations were formulated to relate effective $l$-values to configuration parameters such as the incidence angle, polarisation and frequency (Baghdadi et al., 2006). Álvarez-Mozos et al. (2008) applied the technique developed by Baghdadi et al. (2006) to RADARSAT-1 data over Navarre (Spain), which led to promising soil moisture retrieval results. Alternatively, Rahman et al. (2007) propagated backscatter observations from dry soils (eliminating the effects of soil moisture content) and measurements of RMS height through the IEM for the retrieval of effective correlation length. The use of the latter evidenced a large improvement over the use of field measurements. Finally, in the past few years the effective roughness approach has been successfully applied by numerous studies using both active (e.g. Verhoest et al., 2007a; van der Velde et al., 2007; Joseph et al., 2008) and passive (e.g. Escorihuela et al., 2007; Panciera et al., 2009; de Jeu et al., 2009) microwave remote sensing.

In this study, effective roughness parameters ( $s_{\text {eff }}$ and $\left.l_{\text {eff }}\right)$ are calculated for each $\left(\sigma^{0}, M_{\mathrm{v}}\right)$-observation using the single scattering approximation of the IEM (Fung et al., 1992; Fung, 1994). To this end, a range of $s$ - and $l$-values are propagated through the IEM, after which for every combination of roughness parameters the absolute soil moisture retrieval error is calculated. Next, the respective $s$ - and $l$-values that led to the minimum error are defined as the effective roughness parameters $\left(s_{\mathrm{eff}}, l_{\mathrm{eff}}\right)$. The selected $s$-values ranged from 0.1 to $3.0 \mathrm{~cm}$ for C-band (as the validity condition of the IEM 


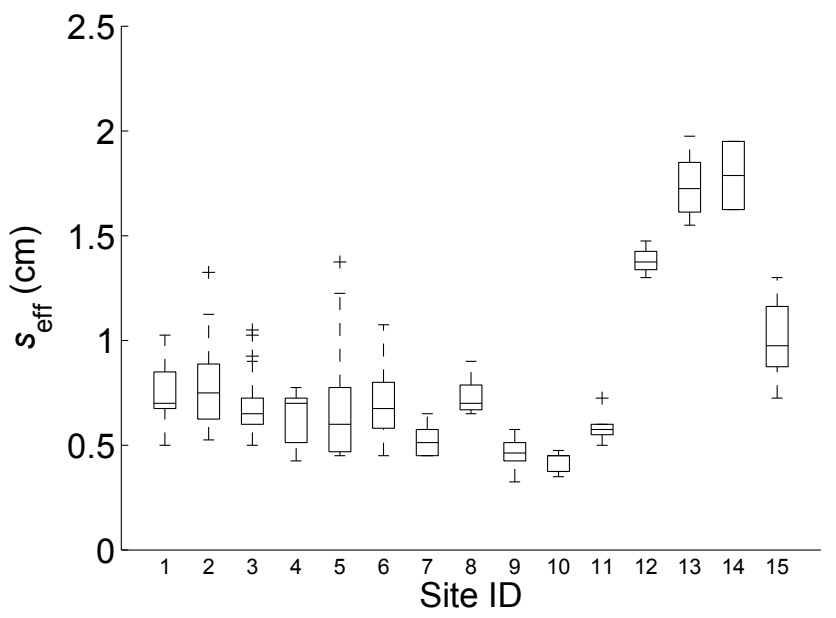

Fig. 3. Box plot of effective RMS heights $\left(s_{\text {eff }}\right)$ per site according to the index shown in Table 1.

requires $k s<3$, with $k$ the wave number) and $0.1-4.0 \mathrm{~cm}$ for L-band, with $\Delta s=0.025 \mathrm{~cm}$. On the other hand, $l$ ranged from 1 to $400 \mathrm{~cm}$, with $\Delta l=1 \mathrm{~cm}$ for both frequencies. As an example, Fig. 2 shows a subset of the typical error patterns that are obtained for (a) C-band and (b) L-band acquisitions. As indicated by this figure, a large number of $(s, l)$-combinations lead to the same minimum soil moisture retrieval error for the given $\left(\sigma^{0}, M_{\mathrm{v}}\right)$, hence, a large number of possible $\left(s_{\text {eff }}, l_{\text {eff }}\right)$-combinations exist. Furthermore, a small deviation from these effective parameters may already cause a large retrieval error, particularly for low values of $s$ and $l$. It is therefore of utmost importance to obtain a precise estimate of the surface roughness. Moreover, it is worth mentioning that the retrieval errors reach a constant level for roughness parameters sufficiently deviating from the effective ones, because the soil moisture retrieval is limited to 2$45 \mathrm{vol} \%$ to avoid unrealistic retrieval values for common soil types (Verhoest et al., 2007b). Finally, Fig. 2 shows that, at C-band, two different $s_{\text {eff-values can be found for the same }}$ $l_{\text {eff }}$, respectively corresponding to a smoother and rougher surface. However, since the selected study fields displayed smooth roughness conditions, we will restrict our analysis to the former.

Soil moisture retrieval based on the IEM requires specific values of $s$ and $l$ as input. Therefore, a single $\left(s_{\text {eff }}, l_{\text {eff }}\right)$ solution for each $\left(\sigma^{0}, M_{\mathrm{V}}\right)$-observation should be obtained. Given the criterion that selected study fields needed to display specific roughness conditions associated with seedbed preparation or rotary tillage, very similar $s$ - and $l$-values may be expected for all fields. Based on this hypothesis, it was decided to set one of the roughness parameters at a predefined value and calibrate the other parameter, such that a unique solution is obtained. Both options, i.e. predefining respectively $s$ and $l$ will be analysed and evaluated for different parameter values. From a physical point of view, setting $s$ at a predefined value may be preferred, since this parameter is known to be more accurately measured in the field. However, it should be stressed that the effective roughness parameters do not necessarily have a physical meaning, but rather should be regarded as tuning parameters for the IEM that may improve soil moisture retrieval. Whether there exists a link between effective and measured parameters is beyond the scope of this paper and could be subject of further research.

\section{Analysis of effective RMS height and correlation length}

This section illustrates the effective RMS heights and correlation lengths, which are obtained by the IEM, with input of in situ soil moisture measurements and predefined $l_{\text {eff }}$ and $s_{\text {eff, }}$ respectively. Furthermore, it demonstrates the variability in effective parameters between different study sites, or even between different fields of the same site and aims at explaining this variability. This analysis forms the basis of the effective roughness modelling (Sect. 5) and consequently the soil moisture retrieval approach (Sect. 6).

Effective RMS heights are obtained by setting the correlation length to a certain fixed value. As an example, Fig. 3 shows a box plot of the obtained RMS heights for $l=10 \mathrm{~cm}$ per study site according to the index in Table 1. This figure illustrates that $s_{\text {eff }}$ is consistently larger at L-band (sites 12-15) than at C-band (sites 1-11), which may be attributed to a failure of the IEM in describing surface roughness as a scale-dependent phenomenon rather than to large in situ differences in roughness, since all fields were relatively smooth and tilled using similar machinery. This discrepancy was already observed by Zribi et al. (1997). Based on IEM simulations of SIR-C/X-SAR and ERASME backscatter data, they found that a good coherence could be obtained at L-band, whereas C-band simulations generally tended to overestimate SAR backscattering. In terms of effective roughness, this tendency will cause decreased effective RMS heights at $\mathrm{C}$-band in order to avoid underestimation of soil moisture. This was also demonstrated by Baghdadi et al. (2004), who found smoother effective roughness parameters at a higher frequency. Therefore, it is important to note that one should be cautious when applying the IEM in combination with a multi-frequency approach - retrieving roughness at one frequency and soil moisture at another using the former derived roughness - as obtained roughness parameters may not be valid at the other frequency. Another conclusion drawn from Fig. 3 is that sometimes large variations exist between the mean $s_{\text {eff }}$-values of different sites (e.g. 14 and 15), or even between the different $s_{\text {eff-values calculated within the same }}$ site (e.g. 6). The large variability of $s_{\text {eff }}$ within one site was found to be caused by temporal changes in combination with sometimes large differences between the different fields. This is illustrated in Fig. 4, which shows the multi-temporal behaviour of $s_{\text {eff }}$ obtained from a series of ENVISAT ASAR 


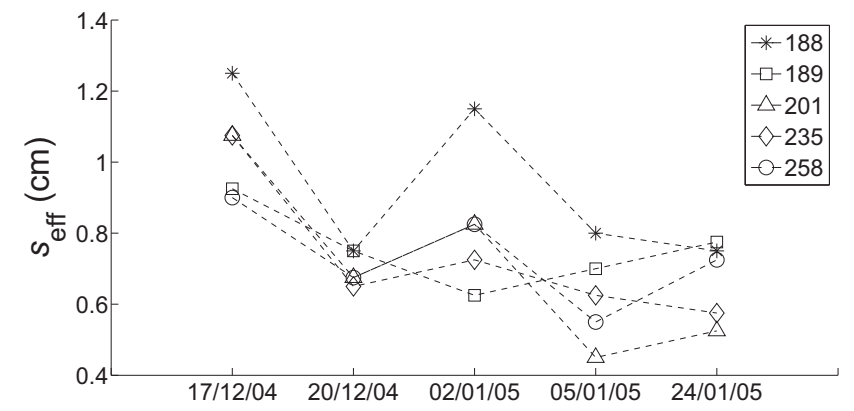

Fig. 4. Multi-temporal behaviour of the effective RMS heights ( $s_{\text {eff }}$ ) obtained from ENVISAT ASAR VV acquisitions over five study fields within the La Tejería (ID 6) site, Spain.

VV acquisitions over five out of the ten study fields in the La Tejería (ID 6) watershed, Spain. As revealed by this figure, the differences in $s_{\text {eff }}$ between subsequent acquisitions range up to $0.5 \mathrm{~cm}$. Therefore, it clearly demonstrates that large errors can be expected if effective roughness parameters of a given acquisition are further used for soil moisture retrieval from subsequent acquisitions. Furthermore, differences in $s_{\text {eff }}$ between fields also range up to about $0.5 \mathrm{~cm}$, even though the same tillage operations were performed. To conclude, an accurate soil moisture retrieval would thus require individual

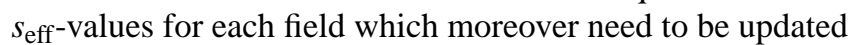
every acquisition. A further analysis of the effective RMS heights reveals that the source of the variability in $s_{\text {eff-values }}$ is twofold: (1) they appear to be affected by the local incidence angle $\theta$ and (2) they are function of the backscatter observation $\sigma^{0}$. Figure 5 demonstrates the linear increase of $s_{\text {eff }}$ with $\sigma^{0}$ for different intervals of $\theta$, as derived from the C-band $\mathrm{HH}$ observations.

Analogously to $s_{\text {eff }}$, effective correlation lengths are obtained by setting the RMS height at a certain fixed value. However, it was observed that L-band generally requires larger $s$-values than C-band. Therefore, in this illustration, $l_{\text {eff-values are calculated for an RMS height arbitrarily set at }}$ $1 \mathrm{~cm}$ for C-band and $2 \mathrm{~cm}$ for L-band. Figure 6 shows a box plot of the obtained correlation lengths per study site according to the site index in Table 1. Again, this figure illustrates the large variability of $l_{\text {eff }}$ between different study sites of the same SAR configuration (e.g. 8 and 10 for C-band VV) and between different fields within the same site (e.g. 15). Furthermore, Fig. 7 displays the relationship between the Cband $\mathrm{HH}$ backscatter observations and their corresponding

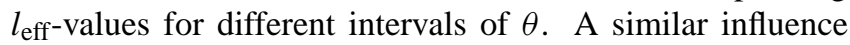
of $\theta$ on the calculation of $l_{\text {eff }}$ was already demonstrated by Baghdadi et al. (2004), who observed a decrease of $l_{\text {eff }}$ as the incidence angle increased. They related this behaviour to an important shortcoming of the IEM in quantifying the relation between surface roughness, local incidence angle and backscatter.

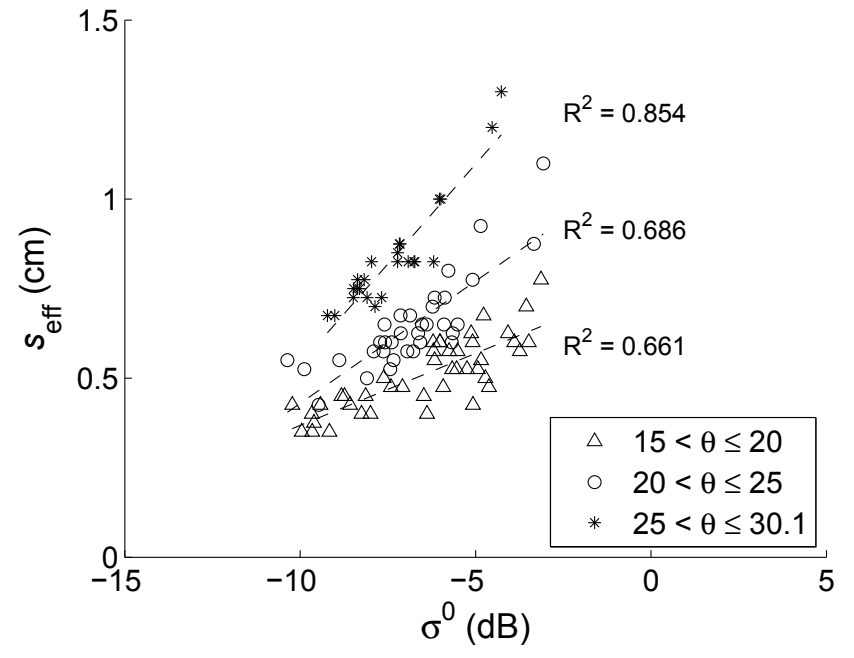

Fig. 5. Dependence of $s_{\text {eff }}$ on the backscatter observations $\left(\sigma^{0}\right)$ for different intervals of incidence angle $\theta$.

\section{Modelling of effective RMS height and correlation length}

The effect of the local incidence angle on the calculation of effective roughness parameters may be reduced by normalising the backscatter observations with respect to a reference incidence angle. To this end, a large number of empirical and theoretical techniques exist, however, each with their specific shortcomings and limitations. Abdel-Messeh and Quegan (2000) compared five of the most widely used techniques and concluded that none of the models performs particularly well, and that no model is markedly the best. For this paper, we choose a theoretical approach initially introduced by Ulaby et al. (1982) and based on the Lambert's law for optics:

$\sigma_{\theta_{\mathrm{ref}}}^{0}=\sigma^{0} \frac{\cos ^{2} \theta_{\mathrm{ref}}}{\cos ^{2} \theta}$

with $\sigma^{0}$ the linear backscatter observation at incidence angle $\theta$ and $\sigma_{\theta_{\text {ref }}}^{0}$ the linear backscatter normalised to a reference incidence angle $\theta_{\text {ref }}$. This normalisation approach assumes that the relationship between the incidence angle and the amount of scattering per unit surface area follows the cosine law. Despite the fact that this model was originally developed for rough surfaces (Abdel-Messeh and Quegan, 2000) and mainly applies to Gaussian surfaces, it has shown to be reasonably representative for many types of terrain (Ulaby et al., 1982). Furthermore, it has the advantage that it does not require any parameter to be fitted, as would be the case for a data-driven normalisation, and has already been successfully applied by other studies (e.g. van der Velde and $\mathrm{Su}$, 2009). Nevertheless, it should be noted that the incidence angle normalisation is certainly not limited to the use of Lambert's law, and basically any normalisation technique could be applied in the frame of the developed soil moisture retrieval approach. Finally, the reference incidence angle was 


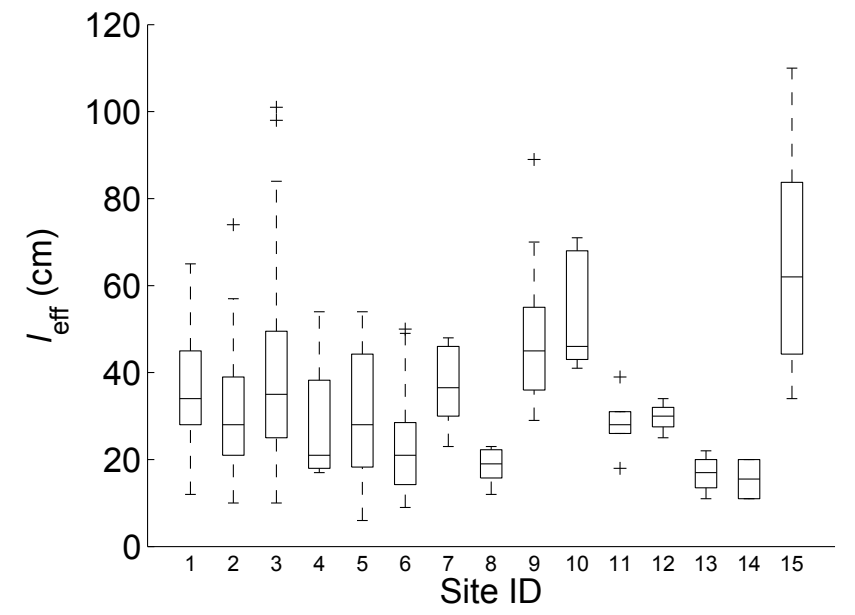

Fig. 6. Box plot of effective correlation lengths $\left(s_{\text {eff }}\right)$ per site according to the index shown in Table 1.

chosen to be $23^{\circ}$ for $\mathrm{C}$-band, corresponding to the standard ERS configuration, and $40^{\circ}$ for L-band, which corresponds to the average value of the L-band observations.

After normalisation of the backscatter coefficients, effective RMS heights and correlation lengths were recalculated. As demonstrated by Figs. 8 and 9, the effect of the incidence angle can be almost completely removed, through which the effective roughness parameters become merely dependent on the normalised backscatter observations $\left(\sigma_{\theta_{\text {ref }}}^{0}\right)$. This relationship can be modelled by a simple linear regression model as follows:

$R_{\mathrm{mod}}=a \sigma_{\theta_{\mathrm{ref}}}^{0}+b+\epsilon$,

with $R_{\text {mod }}$ either the modelled RMS height given a predefined effective correlation length, or the modelled correlation length given a predefined effective RMS height, $a$ and $b$ regression parameters, $\sigma_{\theta_{\text {ref }}}^{0}$ the normalised backscatter (in $\mathrm{dB}$ ) and $\epsilon$ a random error term, usually considered to be zero mean normally distributed. Thus, once the model parameters $a$ and $b$ are fitted, the model allows a straightforward estimation of RMS height or correlation length solely based on a normalised backscatter observation, which removes the need of field work for the purpose of soil moisture retrieval from SAR. Besides, a major advantage of the approach is that the modelled roughness parameters refer to effective rather than measured parameters, as the latter often cause poor soil moisture retrieval results.

The model parameters $a$ and $b$ depend on the roughness parameter to be fixed and on its predefined value. As a consequence, both considerations have an influence on the roughness modelling results, and eventually on the soil moisture retrieval results. Therefore, we will compare the soil moisture retrieval results obtained for different predefined parameter values. To this end, $l_{\mathrm{eff}}$ - and $s_{\mathrm{eff}}$-values are calculated respectively for a range of predefined RMS heights and corre-

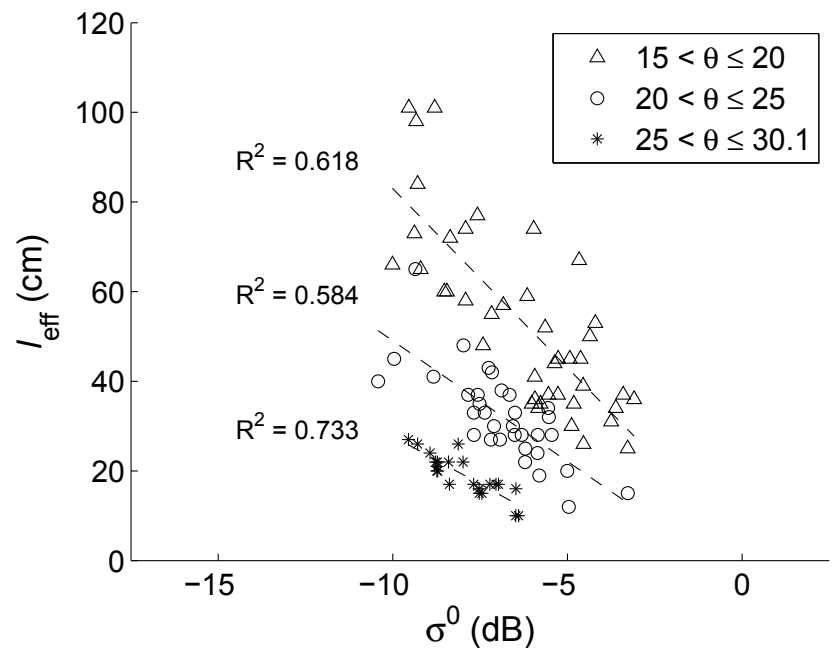

Fig. 7. Dependence of $l_{\text {eff }}$ on the backscatter observations $\left(\sigma^{0}\right)$ for different intervals of incidence angle $(\theta)$.

lation lengths. For each of these predefined parameter values, the regression coefficients $a$ and $b$ are calculated. Next, the normalised backscatter observations can be converted into modelled roughness parameters (according to Eq. 2), which on their turn can be propagated through the inverse IEM for soil moisture retrieval. Finally, for each of the predefined roughness parameters, the RMSE and the determination coefficient $\left(R^{2}\right)$ between the retrieved and observed soil moisture values can be calculated. It should be remarked that the same data set is used for the fitting of the regression models and the evaluation of the soil moisture retrieval results. However, the purpose of this experiment is to analyse the impact of the predefined roughness parameter value and not to perform a throughout validation of the technique based on an independent data set. Such validation will be addressed in the following section.

The predefined RMS heights range from 0.5 to $2.25 \mathrm{~cm}$ for C-band and 1.75 to $3.5 \mathrm{~cm}$ for L-band, with $\Delta s=0.25 \mathrm{~cm}$. Note that larger values for L-band were required, as was concluded from the analysis of $s_{\text {eff }}$ in function of frequency (Sect. 4). On the other hand, the predefined correlation lengths range from 10 to $80 \mathrm{~cm}$ for both frequencies, with $\Delta l=10 \mathrm{~cm}$. Figure 10 shows the RMSE and $R^{2}$-values obtained for the different predefined roughness parameters. It illustrates that generally better soil moisture retrieval results are obtained when modelling $l$ instead of $s$. This is in accordance with Lievens et al. (2009), who found that small errors on RMS height, inherent to its modelling, generally affect the soil moisture retrieval more than larger errors on correlation length. In case of C-band, the choice of the predefined $s$ seems not to be crucial from $0.75 \mathrm{~cm}$ onwards. Nevertheless, the lowest errors are found with $s=1 \mathrm{~cm}$. On the other hand, L-band results seem to be more affected by the selected parameter value and the best results are obtained for $s=2 \mathrm{~cm}$. 


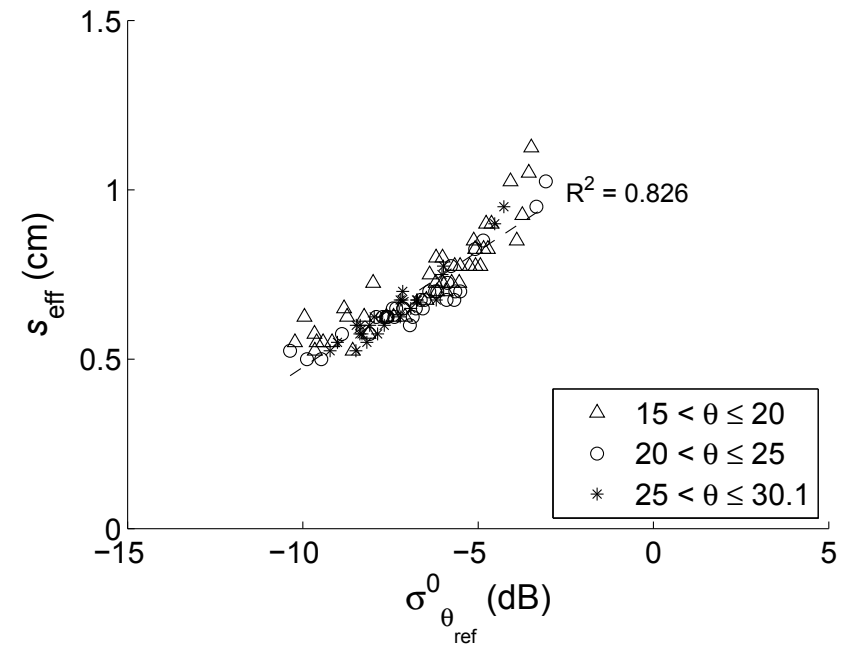

Fig. 8. Dependence of $s_{\text {eff }}$ on the normalised backscatter observations $\left(\sigma_{\theta_{\text {ref }}}^{0}\right)$ for different intervals of incidence angle $\theta$.

Table 2. Regression model parameters and accuracy evaluation.

\begin{tabular}{ccccc}
\hline SAR configuration & $a$ & $b$ & RMSE $(\mathrm{cm})$ & $R^{2}$ \\
\hline C-HH & -5.261 & -8.493 & 3.578 & 0.862 \\
C-VV & -4.330 & -3.841 & 7.007 & 0.533 \\
L-HH & -8.833 & -102.7 & 4.001 & 0.985 \\
\hline
\end{tabular}

The selection of $s$ may be further optimised, particularly in case of L-band HH. However, a general optimisation would require more data and therefore cannot be performed in this study. For the remainder of this paper, we will focus on the selection of RMS height, with $s=1 \mathrm{~cm}$ for C-band and $s=2 \mathrm{~cm}$ for L-band as the predefined roughness parameter values. The final regression model parameters for this set-up are given in Table 2. Furthermore, this table also shows the RMSE- and $R^{2}$-values between the modelled and the effective correlation lenghts. Finally, a scatterplot of the modelled and effective $l$-values is presented in Fig. 11. As revealed by Table 2 and Fig. 11, the modelled roughness values are in agreement with the effective ones, particularly for $\mathrm{C}$ - and L-band HH. For the latter configurations, errors of approximately $4 \mathrm{~cm}$ are encountered. On the other hand, C-band VV is exposed to a larger error of about $7 \mathrm{~cm}$.

\section{Soil moisture retrieval based on modelled effective correlation length}

In the previous section, a model has been developed which allows for the estimation of an effective correlation length based on a normalised backscatter observation. Furthermore, the modelled correlation lengths can be propagated through the inverse IEM for the retrieval of the soil dielectric constant, which on its turn may be converted into volumetric

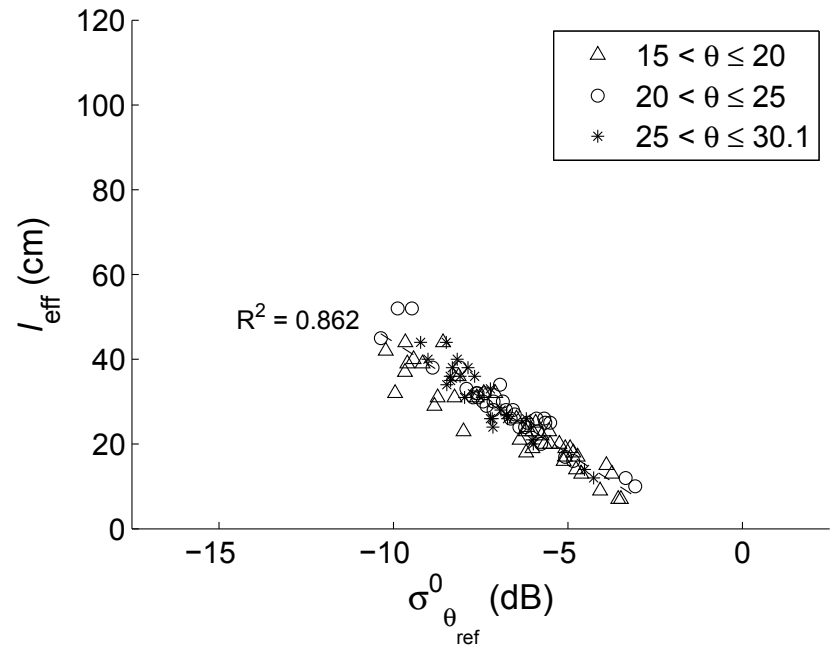

Fig. 9. Dependence of $l_{\text {eff }}$ on the normalised backscatter observations $\left(\sigma_{\theta_{\text {ref }}}^{0}\right)$ for different intervals of incidence angle $(\theta)$.

soil moisture, e.g. using the four-component dielectric mixing model (Dobson et al., 1985). The performance of the regression model will be assessed through cross-validation, rather than through validating on an independent data set because of the limited amount of data available (Hastie et al., 2009). The validation is performed based on three different strategies. The first strategy consists of training the regression model on all data points, and subsequently evaluating it on all data points. In this case, there is no independent data for validation. Nevertheless, the results are useful as a reference for the other strategies. Next, a leave-one-out crossvalidation was performed. To that end, the regression model is trained on all but one data point (i.e. a measurement on one field and one date), and evaluated on that data point. This procedure is repeated for all data points, until a soil moisture value is retrieved for every data point. Finally, all retrieved soil moisture values are pooled together and compared with the measured soil moisture values. In this strategy, the data points are not evaluated independently, as the training data contains measurements on the same field. Therefore, a third strategy was applied, called leave-field-out cross-validation. It consists of training the regression model on all data but those of one field (i.e. measurements on one field and all acquisition dates), and evaluating it on all data of that field. This procedure is repeated for all fields, until a retrieved soil moisture value is obtained for every data point. The retrieved soil moisture values are again pooled together and compared with the measured soil moisture values. Performing both a leave-one-out and a leave-field-out cross validation allows for assessing the method's robustness with respect to a possible effect of the geographical location of the samples. In other words, it allows for checking whether or not there is an influence of measurements sampled within the same agricultural field. It should be noted that, as the third strategy 
Table 3. Cross-validation of the soil moisture retrieval technique

\begin{tabular}{llcc}
\hline & & RMSE (vol\%) & $R^{2}$ \\
\hline C-band HH & strategy 1 & 4.77 & 0.56 \\
& strategy 2 & 4.85 & 0.54 \\
& strategy 3 & 4.90 & 0.53 \\
C-band VV & strategy 1 & 6.17 & 0.4 \\
& strategy 2 & 6.29 & 0.38 \\
& strategy 3 & 6.46 & 0.36 \\
L-band HH & strategy 1 & 4.00 & 0.88 \\
& strategy 2 & 4.22 & 0.87 \\
& strategy 3 & 4.25 & 0.87 \\
\hline
\end{tabular}

still uses training data of other fields of the same study site, no conclusions can be drawn concerning the extrapolation of the regression model to different study sites. Unfortunately, accounting for this dependence as well would require more data sets and is not feasible within this study.

Figure 12 shows the retrieved against the observed soil moisture values for strategies 1 to 3 and each SAR configuration. This figure demonstrates a close agreement between modelled and observed soil moisture, particularly at C-band $\mathrm{HH}$ and L-band $\mathrm{HH}$ configuration. Moreover, very similar results are obtained using the three different validation strategies, demonstrating the robustness of the retrieval approach over different fields. In addition, Table 3 presents the associated RMSE and $R^{2}$-values for each strategy and configuration. The best results are obtained at L-band $\mathrm{HH}$, with errors close to 4 vol\% and $R^{2}$-values of approximately 0.87 . Also the $\mathrm{C}$-band $\mathrm{HH}$ configuration yields accurate results, with error values below 5 vol\% and an $R^{2}$ larger than 0.5 . On the other hand, C-band VV performs slightly worse, with an RMSE $>6$ vol\% and a maximum $R^{2}$ of 0.4 . These larger errors in the case of C-band VV may probably be related to the lower correlation that was observed between the radar backscatter observations and soil moisture, as shown in Fig. 1. Notwithstanding the mediocre results at C-band VV, the developed retrieval technique can still be a step forward towards the operational monitoring of soil moisture from SAR, particularly as it does not require any field measurements and can be achieved using single configuration SAR.

\section{Conclusions}

The paper analysed the behaviour of SAR-derived RMS heights and correlation lengths at two different frequencies, C- and L-band, over a large number of bare or sparsely vegetated seedbed fields. The derived roughness parameters show large differences between frequencies, with RMS height being consistently larger at L-band than at C-band. This is probably due to a failure of the IEM in describ-

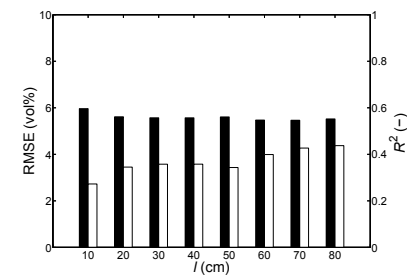

(a)

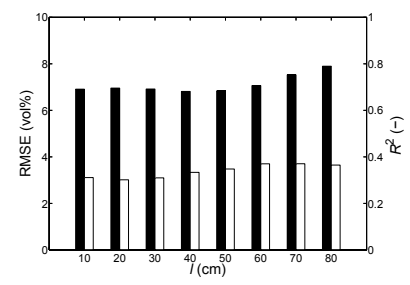

(c)

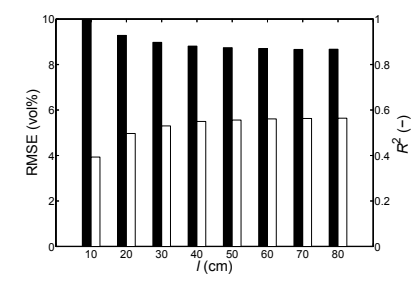

(e)

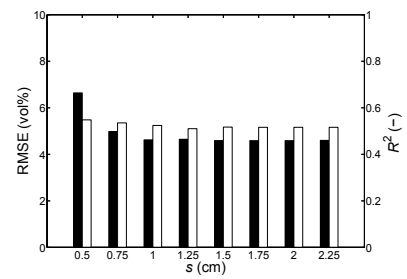

(b)

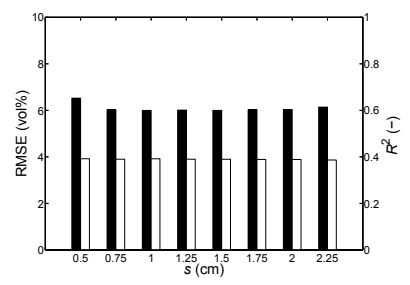

(d)

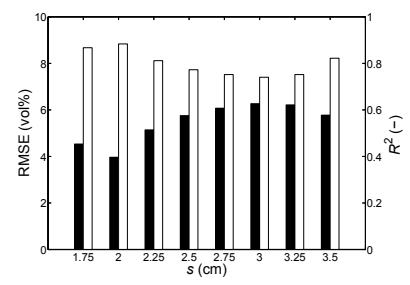

(f)
Fig. 10. Soil moisture retrieval performance in terms of RMSE (black) and $R^{2}$ (white), based on fixed correlation lengths (left) and fixed RMS heights (right) at C-band HH (top), C-band VV (middle) and L-band $\mathrm{HH}$ (bottom) configuration.

ing surface roughness as a scale dependent and complex phenomenon. As a consequence of these large differences, one should be cautious when applying the IEM in combination with a multi-frequency approach for the retrieval of surface parameters from SAR. Furthermore, effective roughness parameters display a large variability between different fields, even though they were tilled using the same machinery, and between successive acquisitions over the same field. Therefore, significant roughness parameterisation errors may be expected if the retrieved parameters from a given SAR acquisition would be transferred to other study fields or acquisitions.

The source of the large variability between effective roughness parameters is twofold: they are affected by the local incidence angle and are function of the observed backscatter coefficients. However, the former effect can be removed by normalising the backscatter observations towards a reference incidence angle. As a result, the effective roughness parameters become merely dependent on the backscatter observations. After predefining one of the roughness parameters, the other parameter can be estimated from the backscatter observations through a simple linear regression model. Subsequently, these estimated roughness parameters can be propagated through the IEM for soil moisture 


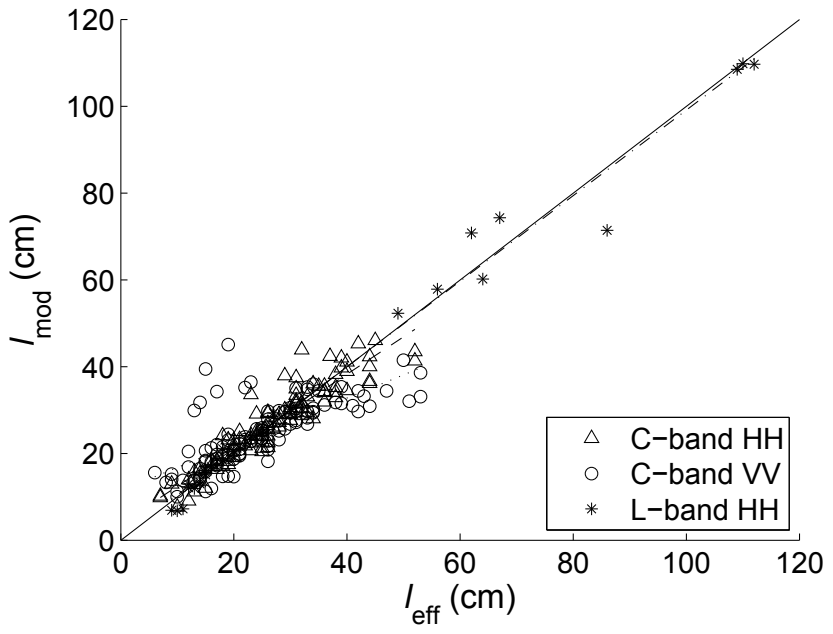

Fig. 11. Modelled correlation length $\left(l_{\text {mod }}\right)$ versus effective correlation length $\left(l_{\text {eff }}\right)$ for the different SAR configurations used.

retrieval. Generally, more accurate soil moisture retrieval results may be expected with the modelling of correlation length. A cross-validation of the soil moisture retrieval approach reveals errors between $4.77-4.90 \mathrm{vol} \%$ for C-band $\mathrm{HH}, 6.17-6.45 \mathrm{vol} \%$ for C-band VV and 4.00-4.25 vol\% for L-band $\mathrm{HH}$. These results highlight the operational potential of the developed retrieval approach and prove its robustness over different fields and data acquisitions.

Notwithstanding the approach was validated based on a large number of different data sets from study sites across Europe, future research requires a further testing of its robustness on additional data, particularly comprising dry soil moisture observations at C-band and more L-band observations. Furthermore, alternative expressions could be designed for other tillage operations or roughness states. Recently, the uncertainty quantification of soil moisture retrieval has become increasingly important, as it serves major applications such as the assimilation of remote soil moisture observations into hydrologic models. Therefore, the development of a method for the estimation of the uncertainty associated with the presented soil moisture retrieval methodology is highly recommended. Finally, with the prolonged operation of ALOS PALSAR and the upcoming SMAP (Soil Moisture Active and Passive) mission, the use of L-band as a recommended frequency for state-of-the-art soil moisture monitoring from SAR definitely needs to be further explored.

Acknowledgements. The research presented in this paper is funded by the Belgian Science Policy Office and the National Research Fund of Luxembourg in the frame of the Stereo II programme project SR/00/100, and by the Spanish Government's National Research, Development and Innovation Plan, project CGL2007$63453 /$ HID. Further, we would like to acknowledge the European Space Agency (ESA) for providing the SAR data in the frame of projects C1P.5038 and C1P.1345 and funding the AgriSAR 2006 campaign. The Canadian Space Agency (CSA) is acknowledged

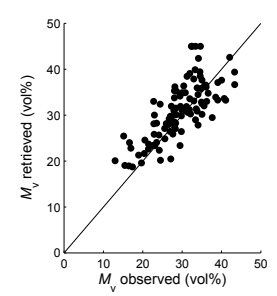

(a)

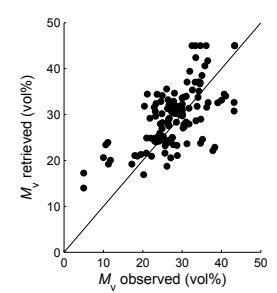

(d)

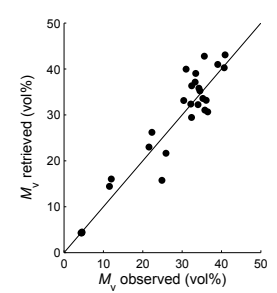

(g)

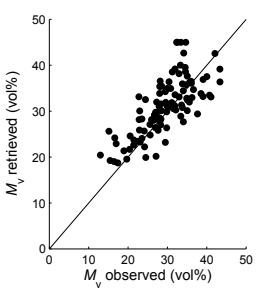

(b)
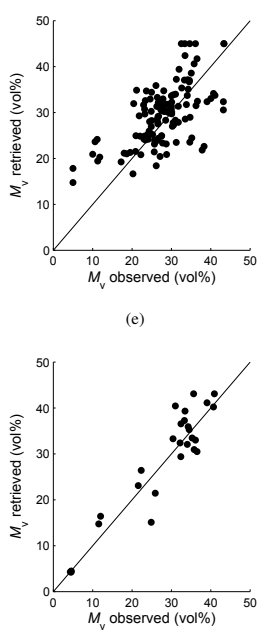

(h)

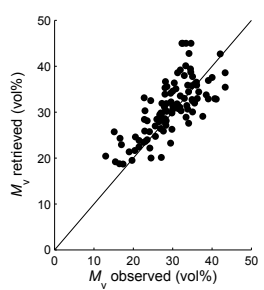

(c)

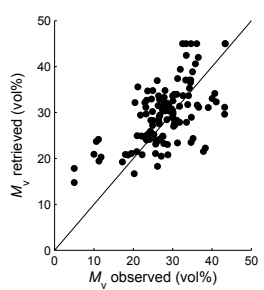

(f)

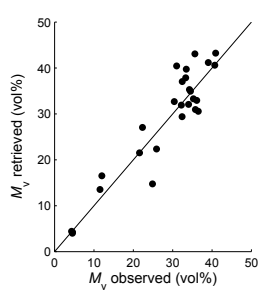

(i)
Fig. 12. Retrieved versus observed in situ soil moisture based on the cross-validation for strategy 1 (left), strategy 2 (middle) and strategy 3 (right), using C-band HH (top), C-band VV (middle) and L-band $\mathrm{HH}$ (bottom) configuration.

for providing the RADARSAT-1 data in concern with project DRU-10-02. Finally, special thanks go to Davy Loete (Ghent University), Francesco Mattia (CNR-ISSIA), all AgriSAR team members and the people from the Universite catholique de Louvain for their help in the collection and distribution of the various data sets.

Edited by: D. F. Prieto

\section{References}

Abdel-Messeh, M. and Quegan, S.: Variability in ERS scatterometer measurements over land, IEEE Geosci. Remote Sens. Lett., 38, 1767-1776, 2000.

Álvarez-Mozos, J., Casalí, J., González-Audícana, M., and Verhoest, N. E. C.: Assessment of the operational applicability of RADARSAT-1 data for surface soil moisture estimation, IEEE T. Geosci. Remote Sens., 44, 913-924, 2006.

Álvarez-Mozos, J., González-Audícana, M., Casalí, J., and Larrañaga, A.: Effective versus measured correlation length for radar-based surface soil moisture retrieval, Int. J. Remote Sens., 29, 5397-5408, 2008.

Álvarez-Mozos, J., Verhoest, N. E. C., Larrañaga, A., Casalí, J., and González-Audícana, M.: Influence of surface roughness spatial 
variability and temporal dynamics on the retrieval of soil moisture from SAR observations, Sensors, 9, 463-489, 2009.

Attema, E. P. W. and Ulaby, F. T.: Vegetation modeled as a water cloud, Radio Sci., 13, 357-364, 1978.

Baghdadi, N., King, C., Chanzy, A., and Wigneron, J. P.: An empirical calibration of the Integral Equation Model based on SAR data, soil moisture and surface roughness measurement over bare soils, Int. J. Remote Sens., 23, 4325-4340, 2002.

Baghdadi, N., Gherboudj, I., Zribi, M., Sahebi, M., King, C., and Bonn, F.: Semi-empirical calibration of the IEM backscattering model using radar images and moisture and roughness field measurements, Int. J. Remote Sens., 25, 3593-3623, 2004.

Baghdadi, N., Holah, N., and Zribi, M.: Calibration of the Integral Equation Model for SAR data in C-band and $\mathrm{HH}$ and VV polarizations, Int. J. Remote Sens., 27, 805-816, 2006.

Beckman, P. and Spizzichino, A.: The Scattering of Electromagnetic Waves from Rough Surfaces, Pergamon, New York, USA, 1963.

Biftu, G. F. and Gan, T. Y.: Retrieving soil moisture from Radarsat SAR data, Water Resour. Res., 35, 1569-1579, 1999.

Bindlish, R. and Barros, A. P.: Parameterization of vegetation backscatter in radar-based soil moisture estimation, Remote Sens. Environ., 76, 130-137, 2001.

Borgeaud, M. and Noll, J.: Analysis of theoretical surface scattering models for polarimetric microwave remote sensing of bare soils, Int. J. Remote Sens., 15, 2931-2942, 1994.

Bryant, R., Moran, M. S., Thoma, D. P., Holifield Collins, C. D., Skirvin, S., Rahman, M., Slocum, K., Starks, P., Bosch, D., and González Dugo, M. P.: Measuring surface roughness height to parameterize radar backscatter models for retrieval of surface soil moisture, IEEE. Geosci. Remote Sens. Lett., 4, 137-141, 2007.

Callens, M., Verhoest, N. E. C., and Davidson, M. W. J.: Parameterization of tillage-induced single-scale soil roughness from 4-m profiles, IEEE T. Geosci. Remote Sens., 44, 878-888, 2006.

Davidson, M. W. J., Le Toan, T., Mattia, F., Satalino, G., Manninen, T., and Borgeaud, M.: On the characterization of agricultural soil roughness for radar remote sensing studies, IEEE T. Geosci. Remote Sens., 38, 630-640, 2000.

de Jeu, R. A. M., Holmes, T. R. H., Panciera, R., and Walker, J. P.: Parameterization of the land parameter retrieval model for Lband observations using the NAFE'05 data set, IEEE. Geosci. Remote Sens. Lett., 6, 630-634, 2009.

Dobson, M. C., Ulaby, F. T., Hallikainen, M. T., and El-Rayes, M. S.: Microwave dielectric behavior of wet soils: Part II Dielectric mixing models, IEEE T. Geosci. Remote Sens., 23, 35-46, 1985.

Escorihuela, M. J., Kerr, Y. H., de Rosnay, P., Wigneron, J. P., Calvet, J. C., and Lemaître, F.: A Simple Model of the Bare Soil Microwave Emission at L-Band, IEEE T. Geosci. Remote Sens., 45, 1978-1987, 2007.

Franceschetti, G., Iodice, A., Maddaluno, S., and Riccio, D.: A fractal-based theoretical framework for retrieval of surface parameters from electromagnetic backscattering data, IEEE T. Geosci. Remote Sens., 38, 641-649, 2000.

Fung, A. K.: Microwave Scattering and Emission Models and Their Applications, Artech House, Boston, MA, 1994.

Fung, A. K., Li, Z., and Chen, K. S.: Backscattering from a randomly rough dielectric surface, IEEE T. Geosci. Remote Sens., 30, 356-369, 1992.
Hajnsek, I., Bianchi, R., Davidson, M., D’Urso, G., GomezSanchez, J. A., Hausold, A., Horn, R., Howse, J., Loew, A., Lopez-Sanchez, J. M., Ludwig, R., Martinez-Lozano, J. A., Mattia, F., Miguel, E., Moreno, J., Pauwels, V. R. N., Ruhtz, T., Schmullius, C., Skriver, H., Sobrino, J. A., Timmermans, W., Wloczyk, C., and Wooding, M.: AGRISAR Optical and Radar Campaign, Tech. rep., European Space Agency, ESA Contract 19974/06/I/LG, 2007.

Hastie, T., Tibshirani, R., and Friedman, J.: The Elements of Statistical Learning, Springer, NY, 2009.

Heitz, S., Matgen, P., Lievens, H., Verhoest, N. E. C., Hissler, C., Pfister, L., and Hoffmann, L.: Active and passive microwave remote sensing of soil moisture: a critical assessment, in: Utilisation de l'imagerie satellite pour l'étude de l'eau dans le sol et le proche sous-sol, Toulouse, France, 2009.

Jester, W. and Klik, A.: Soil surface roughness measurementmethods, applicability, and surface representation, CATENA, 64, 174-192, 2005.

Joseph, A., van der Velde, R., O’Neill, P., Lang, R. H., and Gish, T.: Soil moisture retrieval during a corn growth cycle using L-band $(1.6 \mathrm{GHz})$ radar observations, IEEE T. Geosci. Remote Sens., 46, 2365-2373, 2008.

Leconte, R., Brisette, F., Galarneau, M., and Rouselle, J.: Mapping near-surface soil moisture with RADARSAT-1 synthetic aperture radar data, Water Resour. Res., 40, 1-13, 2004.

Lievens, H. and Verhoest, N. E. C.: On the retrieval of soil moisture in wheat fields from L-band SAR based on Water Cloud modeling, the IEM, and effective roughness parameters, IEEE Geosci. Remote Sens. Lett., accepted, 2010.

Lievens, H., Vernieuwe, H., Verhoest, N. E. C., De Baets, B., Matgen, P., Montanari, M., and Mattia, F.: Soil moisture retrieval from co-polarized ALOS PALSAR backscattering in the Zwalm and Alzette catchments, in: Proceedings of the ALOS PI Symposium, Rhodos, Greece, 2008.

Lievens, H., Vernieuwe, H., Álvarez-Mozos, J., De Baets, B., and Verhoest, N. E. C.: Error in SAR-derived soil moisture due to roughness parameterization: An analysis based on synthetical surface profiles, Sensors, 9, 1067-1093, 2009.

Marzahn, P. and Ludwig, R.: On the derivation of soil surface roughness from multi parametric PolSAR data and its potential for hydrological modeling, Hydrol. Eeath Syst. Sci., 13, 381394, 2009.

Mattia, F. and Le Toan, T.: Backscattering properties of multi-scale rough surfaces, J. Electromagnet. Wave. Appl., 13, 493-527, 1999.

Mattia, F., Le Toan, T., Souyris, J.-C., De Carolis, G., Floury, N., Posa, F., and Pasquariello, G.: The effect of surface roughness on multifrequency polarimetric SAR data, IEEE T. Geosci. Remote Sens., 35, 954-966, 1997.

Mattia, F., Davidson, M. W. J., Le Toan, T., D’Haese, C. M. F., Verhoest, N. E. C., Gatti, A. M., and Borgeaud, M.: A comparison between soil roughness statistics used in surface scattering models derived from mechanical and laser profilers, IEEE T. Geosci. Remote Sens., 41, 1659-1671, 2003.

Moran, M. S., Peters-Lidard, C. D., Watts, J. M., and McElroy, S.: Estimating soil moisture at the watershed scale with satellitebased radar and land surface models, Canad. J. Remote Sens., 30, 805-826, 2004.

Oh, Y. and Kay, Y. C.: Condition for precise measurement of soil 
surface roughness, IEEE T. Geosci. Remote Sens., 36, 691-695, 1998.

Oh, Y., Sarabandi, K., and Ulaby, F. T.: An empirical model and an inversion technique for radar scattering from bare soil surfaces, IEEE T. Geosci. Remote Sens., 30, 370-381, 1992.

Panciera, R., Walker, J. P., Kalma, J. D., Kim, E. J., Saleh, K., and Wigneron, J. P.: Evaluation of the SMOS L-MEB passive microwave soil moisture retrieval algorithm, Remote Sens. Environ., 113, 435-444, 2009.

Prévot, L., Champion, I., and Guyot, G.: Estimating surface soil moisture and leaf area index of a wheat canopy using a dualfrequency ( $\mathrm{C}$ and $\mathrm{X}$ bands) scatterometer, Remote Sens. Environ., 46, 331-339, 1993.

Rahman, M. M., Moran, M. S., Thoma, D. P., Bryant, R., Sano, E. E., Holifield Collins, C. D., Skirvin, S., Kershner, C., and Orr, B. J.: A derivation of roughness correlation length for parameterizing radar backscatter models, Int. J. Remote Sens., 28, 3995-4012, 2007.

Rakotoarivony, L., Taconet, O., Vidal-Madjar, D., Bellemain, P., and Benallègue, M.: Radar backscattering over agricultural bare soils, J. Electromagnet. Wave. Appl., 10, 187-209, 1996.

Rice, S. O.: Reflection of electromagnetic waves from slightly rough surfaces, Commun. Pur. Appl. Math., 4, 361-378, 1951.

Scheiber, R., Keller, M., Fischer, J., Andres, C., Horn, R., and Hajnsek, I.: Radar data processing, quality analysis and level$1 \mathrm{~b}$ product generation for AGRISAR and EAGLE campaigns, in: Proceedings of the AGRISAR and EAGLE campaigns final workshop, Noordwijk, The Netherlands, 2008.

Srivastava, H. S., Patel, P., Sharma, Y., and Navalgund, R. R.: Retrieval of surface roughness using multi-polarized Envisat-1 ASAR data, Geocarto Int., 23, 67-77, 2008.

Srivastava, S. K., Hawkins, R. K., Lubowski, T. I., Banik, B. T., Adamovic, M., and Jefferies, W. C.: RADARSAT image quality and calibration - Update, Adv. Space Res., 23, 1487-1496, 1999.

Su, Z., Troch, P. A., and De Troch, F. P.: Remote sensing of soil moisture using EMAC/ESAR data, Int. J. Remote Sens., 18, 2105-2124, 1997.

Ulaby, F. T., Moore, R. K., and Fung, A. K.: Microwave Remote Sensing: Active and Passive, vol. II, Artech House, Boston, MA, 1982.

van der Velde, R. and Su, Z.: Dynamics in land-surface conditions on the Tibetan Plateau observed by Advanced Synthetic Aperture Radar (ASAR), Hydrolog. Sci. J., 54, 1079-1093, 2009. van der Velde, R., Rientjes, T., Ma, Y., Zhao, Y., and Su, B.: Characterization of the temporal and spatial variability of soil moisture through multi-temporal analysis of ASAR observations, in: 4th International Workshop on the Analysis of Multi-Temporal Remote Sensing Images, Leuven, Belgium, 2007.

Verhoest, N. E. C., Hoeben, R., De Troch, F. P., and Troch, P. A.: Soil moisture inversion from ERS and SIR-C imagery at the Zwalm catchment, Belgium, in: Proceedings of the International Geoscience and Remote Sensing Symposium (IGARSS'00), 2041-2043, Honolulu, Hawaii, 2000.

Verhoest, N. E. C., De Baets, B., Mattia, F., Satalino, G., Lucau, C., and Defourny, P.: A possibilistic approach to soil moisture retrieval from ERS SAR backscattering under soil roughness uncertainty, Water Resour. Res., 43, W07435, doi:10.1029/2006WR005295, 2007a.

Verhoest, N. E. C., De Baets, B., and Vernieuwe, H.: A TakagiSugeno fuzzy rule-based model for soil moisture retrieval from SAR under soil roughness uncertainty, IEEE T. Geosci. Remote Sens., 45, 1351-1360, $2007 \mathrm{~b}$.

Verhoest, N. E. C., Lievens, H., Wagner, W., Álvarez-Mozos, J., Moran, M. S., and Mattia, F.: On the soil roughness parameterization problem in soil moisture retrieval of bare surfaces from Synthetic Aperture Radar, Sensors, 8, 4213-4248, 2008.

Wagner, W., Blöschl, G., Pampaloni, P., Calvet, J.-C., Bizzarri, B., Wigneron, J.-P., and Kerr, Y.: Operational readiness of microwave remote sensing of soil moisture for hydrologic applications, Nord. Hydrol., 38, 1-20, 2007.

Wang, J. R., Hsu, A., Shi, J. C., O’Neill, P. E., and Engman, E. T.: A comparison of soil moisture retrieval models using SIR-C measurements over the Little Washita River watershed, Remote Sens. Environ., 59, 308-320, 1997.

Zribi, M. and Dechambre, M. A.: A new empirical model to retrieve soil moisture and roughness from radar data, Remote Sens. Environ., 84, 42-52, 2002.

Zribi, M., Taconet, O., Le Hégerat-Mascle, S., Vidal-Madjar, D., Emblauch, C., Loumagne, C., and Normand, M.: Backscattering behavior and simulation comparison over bare soils using SIRC/X-SAR and ERASME 1994 data over Orgeval, Remote Sens. Environ., 59, 256-266, 1997.

Zribi, M., Ciarletti, V., and Taconet, O.: Validation of a rough surface model based on fractional Brownian geometry with SIRC and ERASME radar data over Orgeval, Remote Sens. Environ., 73, 65-72, 2000. 